\title{
ASSOCIAÇÃO ENTRE O GRAU DA LACERAÇÃO E DESCRITORES DO QUESTIONÁRIO MCGILL-BR NO PÓS-PARTO VAGINAL
}

\author{
Natália Magalhães Figueiredo ${ }^{1}$ Luciano Marques dos Santos $^{2}$ Maria Alice Leony de \\ Paiva $^{3}$
}

1 Voluntária PEVIC, Graduanda em nome do curso de enfermagem, Universidade Estadual de Feira de Santana e-mail: nat.m_123@hotmail.com

2 Orientador, Prof. Assistente do curso de Enfermagem da Universidade Estadual de Feira de Santana. Pesquisador do Núcleo Interdisciplinar de Estudos sobre Desigualdades em Saúde (NUDES), Universidade Estadual de Feira de Santana, e-mail: lucmarxenfo@yahoo.com.br ${ }^{3}$ participante do Núcleo Interdisciplinar de Estudos sobre Desigualdade em Saúde (NUDES), Departamento de saúde, Universidade Estadual de Feira de Santana, e-mail: Alice_pitombo@hotmail.com

Palavras chaves: Dor, parto normal, períneo.

\section{INTRODUÇÃO}

O parto natural, geralmente está associado a algum grau de trauma, seja por episiotomia ou laceração. As lacerações de $1^{\circ}$ e $2^{\circ}$ grau estão relacionadas a um menor número de complicações, enquanto que as de $3^{\circ}$ e $4^{\circ}$ grau, trás maior preocupação (SMITH et al., 2013). Quando há necessidade de suturar a região, complicações como, por exemplo, a ocorrência de dor pode ocorrer. (SWAIN et al., 2013). Além disso, quanto maior o número de lacerações e mais elevado o grau deste tipo de trauma a dor será expressa de forma mais severa (FRANCISCO et al., 2014).

Algumas escalas foram criadas com esta finalidade, dentre as mesmas encontram-se: Escala Visual Analógica, Escala de Expressões Faciais, Escala numérica, a Escala de Dor Presente Intensidade (PPI) e o Questionário MC Gill (PIMENTA et al., 1979, BELEZA et al., 2012, BRINCAT et al., 2015, CARVALHO et al., 2012).

O questionário MC GILL possui peculiaridades que o distingui das outras escalas, por que além da avaliação da intensidade da dor, possibilitar ao profissional avaliar as características dolorosas, pois o questionário também é composto por descritores que permite as mulheres encontrar palavras que descreve o que elas estão sentindo.

Baseado no exposto, este estudo busca responder ao seguinte questionamento: há associação entre o grau de lacerações perineais e os descritores do Questionário Mc Gill citados por mulheres com dor perineal no pós-parto vaginal?

Assim, o objetivo da pesquisa foi a verificar se existe associação estatisticamente significante entre o grau de laceração e os descritores do questionário McGill-Br.

\section{MATERIAIS E MÉTODOS}

O presente estudo é um recorte da pesquisa intitulada "Condições perineais de mulheres no pós-parto vaginal em uma instituição pública do interior da Bahia”, financiado pelo Edital 001/2012 de Financiamento Interno de Projeto de Pesquisa da Universidade Estadual de Feira de Santana e Fundação de Amparo à Pesquisa do Estado da Bahia, sob a Resolução 171/2012. Trata-se de um estudo exploratório, descritivo e de carater trasversal. A pesquisa foi realizada na cidade de Feira de Santana, tendo como campo do estudo o Alojamento Conjunto para mulheres com partos vaginais no Hospital Inácia Pinto dos Santos (HIPS), conhecido como Hospital da Mulher. Para a caracterização da dor perineal, foram incluídas na amostra um 
total de 239 mulheres no pós-parto vaginal. Sendo utilizado os seguintes critérios de inclusão no estudo: ser puérpera de parto vaginal com feto único e em vértice que apresentou laceração; puérpera com condições psíquicas, psicológicas, clínicas e obstétricas adequadas para responder aos questionamentos dos pesquisadores e preencher os dados do Questionário McGill-Br-MPQ; puérperas com mais de seis horas de pós-parto e que apresentaram dor ou não na região do períneo. Quanto aos critérios de exclusão, pode-se citar: puérpera que não sabiam ler ou escrever e aquelas que apresentaram episiotomia e lacerações perineal espontâneas. Os dados foram coletados no período de setembro de 2012 a dezembro de 2014 . Foi utilizada a técnica da entrevista estruturada através da aplicação de um formulário com questões de identificação das mulheres que foram submetidas ao parto vaginal, condições sóciodemográficas, gestacionais, grau de paridade, dados relacionados à atenção no processo parturitivo, condições do recém-nascido, ocorrência e nível de dor, e descritores do Mc-GillBr. Os dados foram tratados e analisados por meio do pacote estatístico Statistical Package for the Social Sciences (SPSS) versão 22.0 e apresentados sob a forma de tabelas e gráficos. Quanto aos aspectos eticos da pesquisa, a mesma obteve aprovação do CEP através do parecer de nº 842.198, não utilizou Termo de Consentimento Livre e Esclarecido (TCLE), já que o contato da pesquisadora foi apenas com o banco de dados do projeto de pesquisa já referido e a mesma se comprometeu em utilizar o banco de dados bem como suas informações com o cuidado necessário e respeito aos aspectos éticos.

\section{RESULTADOS E DISCUSSÕES}

Na tabela 1, expõe os resultados da associação dos descritores que possui frequência igual ou maior que $30 \%$ para serem utilizados na caracterização da dor das puérperas. Logo, os descritores que vai e vem, que repuxa, latejante da dimensão sensorial discriminativa, leve e incômoda da dimensão Cognitivo-avaliativa e chata da dimensão Motivacional-afetiva foram os que descreveram a dor das puérperas. Entretanto, os descritores que repuxa e chata foram excluídos da associação porque não possuía outros descritores da mesma categoria para verificar o grau de associação. Como variável de exposição foi utilizada na primeira tabela as lacerações de $1^{\circ}$ grau. Não houve associação estatisticamente significativa entre as lacerações de $3^{\circ}$ grau e os descritores, incômoda e leve ( $p$-valor $\left.=0,55\right)$, latejante, que vai e vem (pvalor=0,34). Do mesmo modo, não houve associação estatisticamente significante entre as lacerações de $2^{\circ}$ grau e os descritores, incômoda e leve ( $p$-valor $=0,85$ ), latejante, que vai e vem (p-valor $=0,104)$.

Os descritores da dimensão sensorial estão relacionados a faze aguda do processo de cicatrização. Descritores como "quente, queimando, latejante, podem está associada a um aumento da oferta de sangue para os tecidos danificados durante a etapa inflamatória do processo de cicatrização" (STEEN, 2008).

Em outro estudo que buscou mensurar e caracterizar a dor de puérperas submetidas à perineorrafia os descritores mais frequentes citados pertence às dimensões Sensorialdiscriminativa e Mista. Sendo os seguintes descritores mais escolhidos na dimensão sensorial: latejante, agulhada e dolorida (ambos com frequência de 37,5\%) e fisgada, fina, pontada e ardor, que obtiveram a frequência de 31,2\%, individualmente (ALMEIDA et al., 2011).

Também, é importante salientar que, não ocorreu associação estatisticamente significante entre lacerações de $2^{\circ}$ grau e os descritores, incômoda, leve (p-valor=0.26), latejante, que vai e vem (p-valor=0.53). Também, não ocorreu associação estatisticamente significante entre lacerações de $1^{\circ}$ grau e os descritores, incômoda, leve (p-valor $\left.=0.55\right)$, latejante, que vai e vem $(\mathrm{p}$-valor= 0.34$)$. 
Tabela 1: Verificação da associação entre lacerações de $2^{\circ}$ grau e $3^{\circ}$ grau e os descritores do questionário de dor MCGill-Br, de mulheres com dor em decorrência da perineorrafias secundárias à lacerações espontâneas no parto vaginal, em uma instituição pública, de Feira de Santana (Ba) set/2012-dez/2014.

\begin{tabular}{|c|c|c|c|c|c|c|c|c|}
\hline \multirow{2}{*}{$\begin{array}{c}\text { Tipo de } \\
\text { laceração }\end{array}$} & \multicolumn{2}{|c|}{ Descritores } & \multirow{2}{*}{$\begin{array}{c}\text { p- } \\
\text { valor }\end{array}$} & \multirow{2}{*}{$\begin{array}{c}\text { RP } \\
\text { IC }(95 \%)\end{array}$} & \multicolumn{2}{|c|}{ Descritores } & \multirow{2}{*}{ p- valor } & \multirow{2}{*}{ RP/IC (95\%) } \\
\hline & $\begin{array}{c}\text { Incômoda } \\
\text { n(\%) }\end{array}$ & $\begin{array}{l}\text { Leve } \\
\text { n(\%) }\end{array}$ & & & $\begin{array}{c}\text { Latejante } \\
\text { n }(\%)\end{array}$ & $\begin{array}{c}\text { Que vai e vem n } \\
\qquad(\%)\end{array}$ & & \\
\hline $\begin{array}{c}3^{\circ} \text { grau ou } \\
\text { maior grau }\end{array}$ & $08(30,8)$ & $06(23,1)$ & 0,55 & $\begin{array}{c}1,35 \\
(0,74-2,46)\end{array}$ & $2(12,5)$ & $10(62,5)$ & 0,34 & $0,44(0,12-1,7)$ \\
\hline $2^{\circ}$ grau & $58(37,9)$ & $46(30,1)$ & 0,85 & $\begin{array}{c}1,03 \\
(0,63-1,66)\end{array}$ & $\begin{array}{c}41 \\
(41,8)\end{array}$ & $\begin{array}{c}48 \\
(49)\end{array}$ & 0,104 & $0,36(0,10-1,31)$ \\
\hline $1^{\circ}$ grau & $14(23,3)$ & $19(31,7)$ & & & $12(36,4)$ & $20(60,6)$ & & \\
\hline
\end{tabular}




\section{CONCLUSÃO}

Avaliar a dor no puerpério imediato apenas mensurando a intensidade é considerado insuficiente para fornecer um suporte adequando às mulheres sendo necessário ir além, através da avaliação das suas características subjetivas. O questionário de dor McGill-Br foi criado com esse objetivo, por ajudar na escolha de descritores que melhor expressem o que as pessoas com dor estão sentindo. O questionário é composto por quatro dimensões de descritores que expressam características dolorosas diferentes com nexo a fisiologia da dor.

O presente estudo mostrou que não há associação entre o grau das lacerações perineais e os descritores da dimensão Sensorial-discriminativa e Motivacional-afetiva que caracterizaram a dor das puérperas.

Assim, avaliar a dor decorrente de trauma espontâneo no puerpério imediato possibilita a adoção de medidas mais coerentes no processo de intervenção para promover o alívio da mesma em puérperas laceradas ou episiotomizadas.

Este estudo, ao associar o grau de laceração com os descritores do questionário McGIll$\mathrm{Br}$, expressa a necessidade do desenvolvimento de outras pesquisas que objetive avaliar a subjetividade da dor decorrente de traumas perineais utilizando escalas que a caracterize e não apenas que mensure a intensidade do quadro doloroso. Isso permitirá que os profissionais envolvidos nos cuidados a puérpera compreendam o grau de limitação que a dor pode causar no puerpério e intervenham adequadamente para diminuir as chances de comprometer $o$ desenvolvimento das atividades habituais.

\section{REFERENCIA}

\section{ALMEIDA, C. B et al. PAIN EVALUATION CAUSED BY PERINEORRHAPHY IN}

NORMAL DELIVERY. cuid. fundam. Online, jul./set v 3, n. 3, p. 2126-36, 2011.

BELEZA. A. C. S et al . Mensuração e caracterização da dor após episiotomia e sua relação com a limitação de atividades. Rev Bras Enferm, Brasília 2012, mar-abr; v 65, nº 2, p.264-8. BRINCAT. C, et al. Experiences during the first four years of a postpartum perineal clinic in the USA. International Journal of Gynecology and Obstetrics, v 128 pág. 68- 71, 2015. CARVALHO. E. S. S et al. Como cuidar de pessoas com feridas: desafio para a prática multiprofissional. Salvador: Atualiza Editora, 2012.

FRANCISCO, A. A, et al. Associação entre trauma perineal e dor em primíparas. Revista da Escola de Enfermagem da USP, v. 48, n. spe, p. 39-44, 2014.

PIMENTA C. A de M. et al; Questionário de dor Mc Guill: proposta de adaptação para a língua portuguesa. Rev.Esc.Enf. USP, v.30, n.3, p.473-83, dez, 1979.

SMITH, Lesley A. et al. Incidence of and risk factors for perineal trauma: a prospective observational study. BMC pregnancy and childbirth, v. 13, n. 1, p. 1, 2013.

STEEN, B. M. Understanding perineal pain: women`s descriptions. British journal of midwifery, june, v 16, $n^{\circ} 6,2008$.

SWAIN. J, et al. Putting evidence into practice: A quality activity of proactive pain relief for postpartum perineal pain. Women and Birth v 26 p. 65-70, 2013. 